\title{
The Impact of Silymarin on Improvement of Hepatic Abnormalities in Patients with Severe Preeclampsia: A Randomized Clinical Trial
}

\author{
Fahimeh Kaveh Baghbahadorani ${ }^{1}$, Sepideh Miraj $^{2}$
}

${ }^{1}$ M.D., Gynecologist, Faculty of Medicine, Shahrekord University of Medical Sciences, Shahrekord, Iran

${ }^{2}$ M.D., Gynecologist, Fellowship of Infertility, Assistant Professor, Faculty of Medicine, Shahrekord University of Medical Sciences, Shahrekord, Iran

Type of article: Original

\begin{abstract}
Background: Preeclampsia is a pregnancy-specific disorder, associated with increased blood pressure and proteinuria, and in extreme cases it can also cause liver and kidney problems.

Objective: To determine the impact of silymarin on the improvement of severe preeclampsia.

Methods: This randomized clinical trial was conducted at Hajar Hospital in Shahrekord, Iran, from April 2014 to September 2015. Sixty patients whose pregnancy had ended as a result of severe preeclampsia, were entered into the study. Patients were randomly divided into two groups of thirty study and control groups. In addition to current treatment for preeclampsia, case groups were administered $70 \mathrm{mg}$ of silymarin, three and twenty four hours after the termination of pregnancy. The control group received placebo at the same time. The blood pressure and AST, ALT, ALP, LDH, uric acid, bilirubin and kidney tests were compared at the baseline and 12, 36 and 60 hours post- measurements in two groups by SPSS software, version 22, by the ANOVA test, and by the independent-samples t-test.

Results: AST and ALT liver enzyme levels decreased significantly 36 and 60 hours after the termination of pregnancy in the study group compared to the control group $(\mathrm{p}<0.01)$.

Conclusion: Silymarin is used to treat liver disorders, and has beneficial results. It seems that this drug can be used for accelerating improvement of liver disorders in severe preeclampsia. However, adjusting the dose of the drug for the treatment of liver disorders in severe preeclampsia requires further studies.

Clinical trial registration: The trial was registered at the Iranian Registry of Clinical Trials (http://www.irct.ir) with the Irct ID: IRCT201509042388/N1.

Funding: Shahrekord University of Medical Sciences supported this research (project no. 2006).

Keywords: Preeclampsia, Silymarin, Liver enzymes
\end{abstract}

\section{Introduction}

Preeclampsia is a multifactorial disease and is a major cause of maternal and fetal morbidity and mortality. Preeclampsia is regarded as a sudden onset of hypertension and proteinuria or end-organ failure after twenty weeks of pregnancy in women who otherwise previously had normal blood pressure. Clinical protests of preeclampsia can appear at any time from the second half of the pregnancy to the first few days after delivery. Cases of severe preeclampsia may cause the mother to suffer from disorders such as pulmonary edema, cerebral hemorrhage, convulsions, impaired hepatic and renal impairment and even death. It can cause complications in newborns such as preterm delivery, stillbirth, neonatal growth restriction and neonatal admission to intensive care. (1). Characteristics of preeclampsia include: systolic blood pressure greater than or equal to $160 \mathrm{~mm} \mathrm{Hg}$ and diastolic blood pressure greater than or equal to $110 \mathrm{~mm} \mathrm{Hg}$, severe and persistent headache, visual disturbances, upper abdominal pain, thrombocytopenia, microangiopathic hemodialysis, increase in creatinine and liver enzymes (2). Risk factors of preeclampsia include pregnancy at an early or old age, first pregnancy, history of chronic hypertension, obesity, multifetal delivery and a history of preeclampsia in a previous pregnancy (3). The exact pathogenesis of

\section{Corresponding author:}

Assistant Professor Dr. Sepideh Miraj, Faculty of Medicine, Shahrekord University of Medical Sciences, Shahrekord, Iran. Email: miraj.sepideh@gmail.com

Received: April 03, 2016, Accepted: September 20, 2016, Published: August 2017

iThenticate screening: September 20, 2016, English editing: October 17, 2016, Quality control: December 28, 2016

(C) 2016 The Authors. This is an open access article under the terms of the Creative Commons Attribution-NonCommercialNoDerivs License, which permits use and distribution in any medium, provided the original work is properly cited, the use is non-commercial and no modifications or adaptations are made. 
preeclampsia is not clear yet, but several hypotheses have been proposed including the impact of immunological factors, coagulation disorders, lack of adaptation of the mother, regarding cardiovascular changes or inflammatory compliance during pregnancy, genetic factors, nutritional factors and increased production of oxygen free radicals $(3,4)$. The exact pathogenesis of preeclampsia is still not known, but many hypotheses about the impact of factors such as immunologic, coagulation disorders, incorrect match of mother with cardiovascular changes or inflammatory pregnancy, genetic factors, nutritional factors and increased production of oxygen free radicals and consequently peroxidation of plasma lipids that can cause endothelial damage and placental vascularization in preeclampsia have been proposed $(3,4)$. Several studies pointed to the imbalance between antioxidants and lipid peroxidation in preeclampsia. Silymarin is an extract of silymarin herb and a pharmaceutical plant. Milk thistle (Silybum) was considered sacred in ancient times as a medicine, and has a long history in traditional medicine. In the first century AD, a Romanian biologist called Pliny stated that the milky juice of this plant is useful to induce the secretion of bile. In 1968, scientists separated three specific molecules protecting the liver from the plant called silibinin, Silydianin, Silychristin which today are collectively known as silymarin. The therapeutic use of the plant dates back 2000 years, and in ancient Greek sources, it is stated as a liver protective agent $(5,6)$. In recent times, several studies have investigated the impact of silymarin on various liver disorders and in most cases, it has many beneficial effects and no significant side effects mentioned. Due to the fact that one of the typical complications of patients with preeclampsia is liver complications, in this study the effect of silymarin on various complications of severe preeclampsia in women due to the termination of their pregnancy, has been investigated. Herbal medicine has always been a cost effective and less expensive remedy (5-7). Silymarin is a herbal medicine with high therapeutic effects (8).

\section{Material and Methods}

\subsection{Trial design and participants}

The study was a double-blind clinical trial intervention with Irct code: 201509042388/N1 and the study population was selected among the patients hospitalized in Hajar hospital of Shahrekord whose pregnancy was terminated because of severe preeclampsia. This study was carried out between April 2014 and September 2015.Considering inclusion criteria, the patients who were eligible for the study were selected and a full description of preeclampsia and the type of study was given to them. A total of sixty people who had consented to enter the study and signed a consent form were enrolled. Figure 1 shows the CONSORT flowchart of the study.

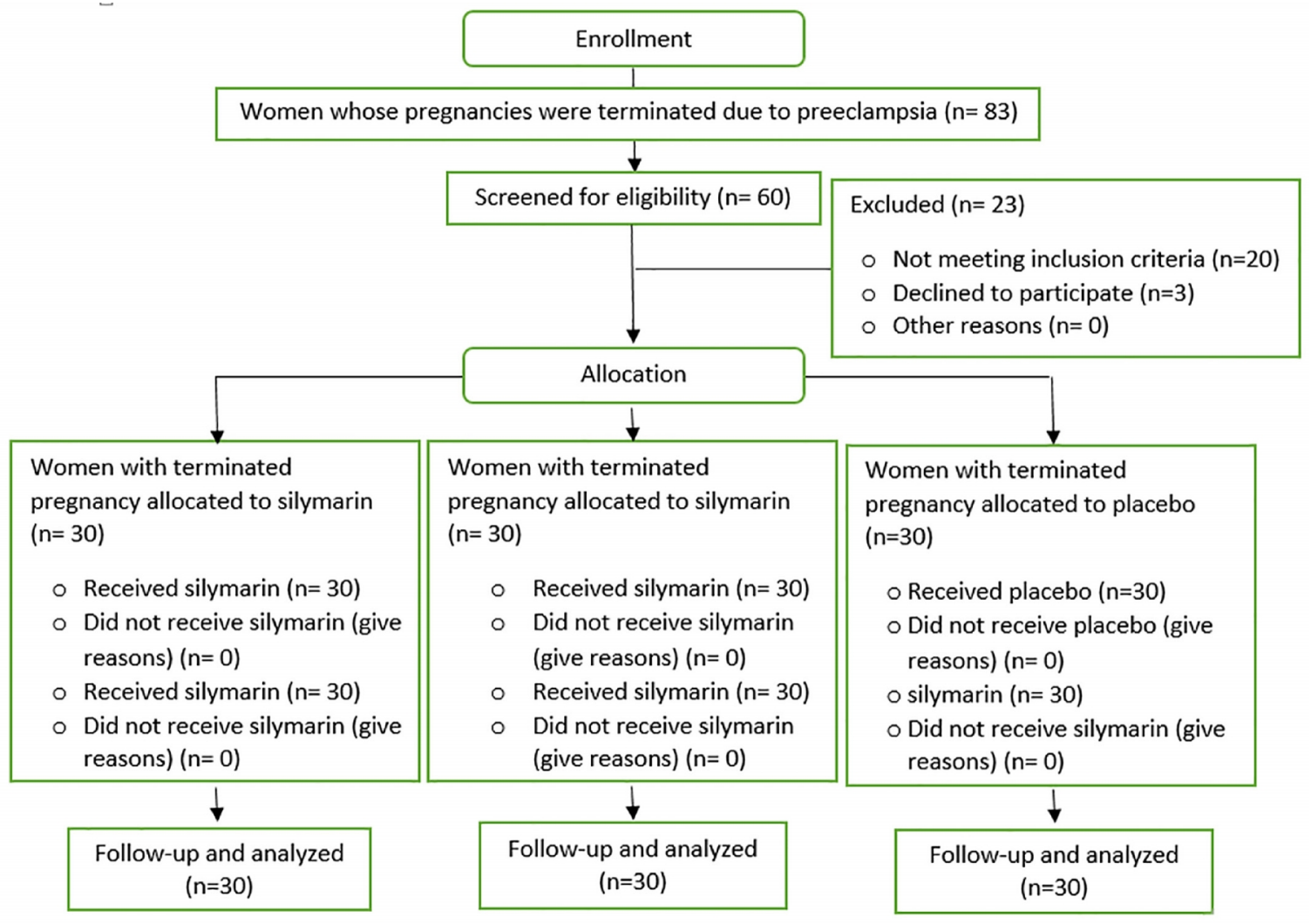

Figure 1. The CONSORT flow diagram of the trial 


\subsection{Selection criteria}

\subsubsection{Inclusion criteria:}

1) The mother's age was between 20 and 30 years.

2) BMI of mothers was between 20 and 24 are.

3) When gestational age was between 35 and 42 weeks.

4) The patient's blood pressure before pregnancy termination was greater than $140 / 90 \mathrm{~mm} \mathrm{Hg}$.

5) The presence of proteinuria in random urine sample before pregnancy termination.

6) Absence of history of hypertension, diabetes, kidney disease, collagen vascular disease and other cardiovascular diseases.

7) Nulliparous mothers and abortion or no previous pregnancy.

8) No smoking or alcohol consumption history in mother.

9) Singleton not molar pregnancies.

10) Termination of pregnancy is indicated for patients with severe preeclampsia.

11) Patient satisfaction in participating in the study and the consent form is signed.

12) Lack of preeclampsia before inclusion in the study

\subsubsection{Exclusion criteria:}

1) The lack of consent to participate in the study

2) Sufferance of the patient from eclampsia

\subsection{Interventions}

After examination of inclusion criteria, sixty patients entered the study and were divided into two experiment and control groups. The patients were assigned into two groups mainly based on randomness, however, it was attempted that the patients in both groups were matched for age and initial lab results. Having entered patients to study, their basic information was recorded in their related form. The patient's age was calculated based on his year of birth and was recorded in his form. Patient weight was measured using a weigh scale analog and was recorded based on $\mathrm{kg}$ in the form of each patient. Patient's height and BMI was measured by a tape meter based on meter (M) and BMI was measured based on kilograms per square meter $\left(\mathrm{kg} / \mathrm{m}^{2}\right)$. The patient's type of delivery (vaginal delivery or cesarean) was extracted from the patients' files and recorded in the related form of each patient. Birth weight of babies was measured using an infant measuring device and was recorded in the related form of each patient. In the baseline, survey results for each patient were extracted from their file and recorded in their related form including systolic and diastolic blood pressure, results of hepatic tests including ALT, AST and ALP and total bilirubin and direct bilirubin, and uric acid, BUN, Cr, proteinuria in random urine samples. In both experiment and control groups, patients received routine treatment for severe preeclampsia including magnesium sulfate and hydralazine intake if blood pressure was more than 110/160. In the study group, three hours after the termination of pregnancy (three hours after birth), $70 \mathrm{mg}$ of Silymarin was administered orally and this drug was repeated twenty four hours later. In the control group, placebo was administered at the same time frames ( 3 and 24 hours later). 12, 36 and 60 hours after drug administration, the following tests were repeated: Liver enzymes, AST, ALT, ALP, total and direct Bilirubin, BUN, in random urine samples and the results were recorded in the checklist of each patient. Systolic and diastolic blood pressure of patients was measured every three hours using a mercury sphygmomanometer and was recorded in the checklists. Patients were also monitored in terms of frequency of hypertension crisis and the need for hydralazine. Finally, the two groups were compared in terms of age, BMI, birth weight, gestational age at termination of pregnancy, blood pressure, levels of liver enzymes ,AST, ALT, ALP , total bilirubin, direct bilirubin, number of blood pressure crisis.

\subsection{Outcomes}

The primary outcomes of our analyses were the baseline rate of age, BMI, gestational age, systolic blood pressure $(\mathrm{mmHg})$, diastolic blood pressure $(\mathrm{mmHg})$, average natal weight at birth $(\mathrm{g})$, platelet count $(\mathrm{mm} 3 \mathrm{of}$ blood) of the two groups. Also, the secondary outcomes from the analyses were the platelet count at 12, 36, and 60 hours post intervention and the patients' satisfaction with the drug in terms of convenience of use.

\subsection{Sample size}

The sample size was calculated to be sixty subjects. This sample size was calculated based on the results of previous studies (39) by assuming the test power of $80 \%$ and a confidence level of $95 \%$ and using the following formula: $\mathrm{n}=$ $\left(\mathrm{Z}_{1-\alpha / 2}+\mathrm{Z}_{1-\beta}\right)^{2}\left(\mathrm{P}_{1}\left(1-\mathrm{P}_{1}\right)+\mathrm{P}_{2}\left(1-\mathrm{P}_{2}\right)\right) /\left(\mathrm{P}_{1}-\mathrm{P}_{2}\right)^{2}$, where: $\mathrm{n}=$ Sample size, $\mathrm{Z}_{1-\alpha / 2}=1.96, \alpha=5 \%$ for two-tailed hypothesis, $Z_{1-\beta}=0.842, \beta=20 \%$ (study power $=80 \%$ ), $P=$ Probability of the main outcome. 


\subsection{Randomization and blinding}

In this clinical trial, stratified randomization was used with the baseline of the termination of pregnancy and diagnosis of severe preeclampsia. After examination of the inclusion criteria, sixty patients entered the study and were divided into two groups, a patients group and a control group. The patients were assigned randomly to the two groups and the priority of reference to the clinic to receive either oral silymarin or placebo. Both drugs were of the same size and color. Randomization was carried out by one of the researchers, who did not have a role in the treatment of the participants. The allocation concealment was carried out by the researcher who was responsible for the randomization. After being allocated randomly to the groups, all participants were referred to the hospital's pharmacy to receive their medicine. Patients were matched in the two groups for age, BMI, and initial hepatic and platelet enzyme. Also, the outcomes of the study were recorded by the first-year Obstetrics \& Gynecology residents and midwives of the delivery ward who made no other contribution to the study.

\subsection{Statistical methods}

The two groups were compared in terms of age, BMI, baby's birth weight, gestational age at the time of termination of pregnancy, and platelet count, and the data were analyzed using SPSS version 22 (IBM $\odot$ Corp., Armonk, NY, USA). We used the independent-samples t-test, and ANOVA to analyze the primary and secondary outcomes.

\subsection{Ethics of biomedical research}

All procedures performed in studies involving human participants were in accordance with the ethical standards of the institutional and/or national research committee and with the 1964 Helsinki declaration and its later amendments or comparable ethical standards. Informed consent: Informed consent was obtained from all individual participants included in the study. Ethical no. of this research is 92-10-13.

\section{Results}

This study was performed to evaluate the effect of silymarin on hepatic abnormalities in patients with severe preeclampsia at Hajar hospital in Shahrekord. The following results have been achieved. In this study, two groups of thirty women with severe preeclampsia who had been involved in the termination of pregnancy participated. Their characteristics including age, body mass index, gestational age, systolic blood pressure, diastolic blood pressure is given in Table 1. In this study, two groups of 30 women with severe preeclampsia who had been involved in the termination of pregnancy participated. Their characteristics including age, body mass index, gestational age, proteinuria, systolic blood pressure, diastolic blood pressure, platelet at baseline is given in Table 1. Proteinuria and liver enzymes at baseline, 12,36 and 60 hours later was measured and the results are shown in Table 2. The trend of AST enzyme in the intervention group was different from that of the control group and the reducing slope is more intense in the intervention group (Figure 2). The average number of blood pressure crisis during the study (systolic blood pressure greater than or equal to $160 \mathrm{~mm} \mathrm{Hg}$ and diastolic blood pressure greater than or equal to $110 \mathrm{~mm} \mathrm{Hg}$ ) in the intervention group was $2.1 \pm 0.7$, and in the control group was $2.4 \pm 0.5$ showing no significant difference between the two groups $(\mathrm{p} \geq 0.05)$.

Table 1. Characteristics of the basic variables in both intervention and control groups

\begin{tabular}{|l|l|l|l|}
\hline \multirow{2}{*}{ Variables } & Control group & Study group & \multirow{2}{*}{ p-value } \\
\cline { 2 - 3 } & Mean \pm SD & Mean \pm SD & \\
\hline Age $($ year) & $25.4 \pm 3.04$ & $25.5 \pm 2.83$ & 0.88 \\
\hline BMI $\left(\mathrm{kg} / \mathrm{m}^{2}\right)$ & $23.5 \pm 0.54$ & $23.6 \pm 0.59$ & 0.89 \\
\hline Gestational age & $37 \pm 1.5$ & $36.9 \pm 1.4$ & 0.93 \\
\hline Proteinuria at the baseline (based on the Rip stick) & $2.4 \pm 0.4$ & $2.6 \pm 0.6$ & 0.83 \\
\hline Systolic blood pressure $(\mathrm{mmHg})$ & $160.4 \pm 4.3$ & $163.8 \pm 1.2$ & 0.54 \\
\hline Diastolic blood pressure $(\mathrm{mmHg})$ & $96.4 \pm 5.4$ & $99.1 \pm 5.7$ & 0.67 \\
\hline LDH at the baseline (unit/lit) & $7.9 \pm 6.519$ & $8.3 \pm 5.532$ & 0.7 \\
\hline The average weight of newborn $(\mathrm{gr})$ & $3167.7 \pm 53.8$ & $3129.8 \pm 51.6$ & 0.79 \\
\hline ALP at the baseline $($ unit/lit) & $581.8 \pm 19.1$ & $578.3 \pm 14.6$ & 0.53 \\
\hline Uric acid at the baseline $(\mathrm{mg} / \mathrm{dI})$ & $6.1 \pm 0.5$ & $6.4 \pm 0.8$ & 0.71 \\
\hline Total bilirubin at the baseline $(\mathrm{mg} / \mathrm{dI})$ & $1.25 \pm 0.59$ & $1.14 \pm 0.67$ & 0.68 \\
\hline Direct bilirubin at the baseline $(\mathrm{mg} / \mathrm{dI})$ & $0.69 \pm 0.19$ & $0.71 \pm 0.15$ & 0.81 \\
\hline BUN at the baseline $(\mathrm{mg} / \mathrm{dI})$ & $18.2 \pm 1.3$ & $17.7 \pm 1.8$ & 0.72 \\
\hline Creatinine at the baseline $(\mathrm{mg} / \mathrm{dI})$ & $0.69 \pm 0.18$ & $0.72 \pm 0.13$ & 0.84 \\
\hline AST at the baseline(unit/lit) & $97.5 \pm 37.5$ & $99.8 \pm 40.7$ & 0.82 \\
\hline AIT at the baseline(unit/lit) & $105.1 \pm 43.2$ & $101.7 \pm 44.4$ & 0.91 \\
\hline
\end{tabular}


http://www.ephysician.ir

Table 2. The liver enzymes and platelet count during the study

\begin{tabular}{|c|c|c|c|c|}
\hline \multirow{2}{*}{\multicolumn{2}{|c|}{ Variables }} & Study group & Control group & \multirow[t]{2}{*}{ p-value } \\
\hline & & Mean \pm SD & Mean \pm SD & \\
\hline \multirow[t]{4}{*}{ AST (unit/lit) } & At baseline & $99.8 \pm 40.70$ & $97.5 \pm 37.5$ & 0.82 \\
\hline & After 12 hours & $88.3 \pm 33.7$ & $93.8 \pm 32.6$ & 0.64 \\
\hline & After 36 hours & $60.2 \pm 23$ & $75.8 \pm 25.2$ & 0.01 \\
\hline & After 60 hours & $43.7 \pm 11.7$ & $60.4 \pm 16$ & 0.0001 \\
\hline \multirow[t]{4}{*}{ AIT (unit/lit) } & At baseline & $101.7 \pm 44.2$ & $105.1 \pm 43.2$ & 0.91 \\
\hline & After 12 hours & $88.2 \pm 34$ & $92.1 \pm 33.1$ & 0.73 \\
\hline & After 36 hours & $58.2 \pm 24.9$ & $74.8 \pm 24.4$ & 0.01 \\
\hline & After 60 hours & $40.2 \pm 9.2$ & $59.2 \pm 16.4$ & 0.0001 \\
\hline \multirow[t]{4}{*}{ LDH (unit/lit) } & At baseline & $532.5 \pm 8.3$ & $519.6 \pm 7.9$ & 0.7 \\
\hline & After 12 hours & $524.2 \pm 21$ & $519.3 \pm 19.4$ & 0.53 \\
\hline & After 36 hours & $503.6 \pm 16.4$ & $499.3 \pm 12.3$ & 0.48 \\
\hline & After 60 hours & $489.2 \pm 18.1$ & $483.1 \pm 11.2$ & 0.66 \\
\hline \multirow[t]{4}{*}{ AIP (unit/lit) } & At baseline & $578.3 \pm 14.6$ & $581.8 \pm 19.1$ & 0.53 \\
\hline & After 12 hours & $561.1 \pm 31.2$ & $553.6 \pm 21.4$ & 0.68 \\
\hline & After 36 hours & $558.5 \pm 18.4$ & $550.3 \pm 26.7$ & 0.61 \\
\hline & After 60 hours & $461.3 \pm 31.2$ & $457.1 \pm 29.3$ & 0.59 \\
\hline \multirow[t]{4}{*}{ Total bilirubin (mg/dl) } & At baseline & $1.14 \pm 0.67$ & $1.25 \pm 0.59$ & 0.68 \\
\hline & After 12 hours & $1.3 \pm 0.31$ & $1.2 \pm 0.3$ & 0.54 \\
\hline & After 36 hours & $1.2 \pm 0.25$ & $1.27 \pm 0.18$ & 0.62 \\
\hline & After 60 hours & $1.31 \pm 0.21$ & $1.24 \pm 0.31$ & 0.43 \\
\hline \multirow[t]{4}{*}{ Direct bilirubin $(\mathrm{mg} / \mathrm{dl})$} & At baseline & $0.71 \pm 0.15$ & $0.69 \pm 0.19$ & 0.81 \\
\hline & After 12 hours & $0.67 \pm 0.23$ & $0.71 \pm 0.24$ & 0.76 \\
\hline & After 36 hours & $0.72 \pm 0.18$ & $0.67 \pm 0.21$ & 0.38 \\
\hline & After 60 hours & $0.74 \pm 0.23$ & $0.68 \pm 0.17$ & 0.31 \\
\hline \multirow[t]{4}{*}{ Uric acid $(\mathrm{mg} / \mathrm{dl})$} & At baseline & $6.4 \pm 0.8$ & $6.1 \pm 0.5$ & 0.71 \\
\hline & After 12 hours & $5.9 \pm 0.91$ & $5.7 \pm 0.81$ & 0.65 \\
\hline & After 36 hours & $5.7 \pm 0.79$ & $5.5 \pm 0.53$ & 0.6 \\
\hline & After 60 hours & $4.9 \pm 0.42$ & $5.1 \pm 0.53$ & 0.78 \\
\hline \multirow[t]{4}{*}{$\mathrm{BNU}(\mathrm{mg} / \mathrm{dl})$} & At baseline & $17.7 \pm 1.8$ & $18.2 \pm 1.3$ & 0.72 \\
\hline & After 12 hours & $16.1 \pm 5.4$ & $17.1 \pm 6.2$ & 0.47 \\
\hline & After 36 hours & $15.9 \pm 6.1$ & $16.4 \pm 5.6$ & 0.49 \\
\hline & After 60 hours & $14.9 \pm 5.7$ & $15.1 \pm 6.5$ & 0.532 \\
\hline \multirow[t]{4}{*}{ Creatinine (mg/dl) } & At baseline & $0.72 \pm 0.13$ & $0.69 \pm 0.18$ & 0.84 \\
\hline & After 12 hours & $0.74 \pm 0.23$ & $0.72 \pm 0.19$ & 0.79 \\
\hline & After 36 hours & $0.81 \pm 0.18$ & $0.79 \pm 0.17$ & 0.74 \\
\hline & After 60 hours & $0.76 \pm 0.21$ & $0.75 \pm 0.22$ & 0.78 \\
\hline \multirow[t]{4}{*}{ Proteinuria } & At baseline & $2.6 \pm 0.6$ & $2.4 \pm 0.4$ & 0.83 \\
\hline & After 12 hours & $2.1 \pm 0.41$ & $1.9 \pm 0.6$ & 0.62 \\
\hline & After 36 hours & $1.8 \pm 0.53$ & $1.7 \pm 0.48$ & 0.7 \\
\hline & After 60 hours & $1.4 \pm 0.34$ & $1.6 \pm 4.1$ & 0.41 \\
\hline
\end{tabular}

As shown in Figure 3, the trend of enzyme in the intervention group is different from that of the control group and the decreasing slope of ALT is more intense in the intervention group. In examining the AST values at baseline and after twelve hours in both intervention and control groups, there were no statistically significant differences between the two groups, but examining its values after 36 and 60 hours showed that there was a significant difference between the two groups. Significant differences between the intervention and control groups 36 and 60 hours after entrance to the study could be due to the positive effects of silymarin on improvement of hepatic disorders. Lack of statistically significant difference between the two groups after twelve hours may be due to the need for more time or need for a higher dose of silymarin to be effective. In this study, ALT values twelve hours after entering the study showed no significant differences between the intervention and control groups; however, there was significant difference between the two groups regarding to these values 36 and 60 hours after the entrance to the study. 


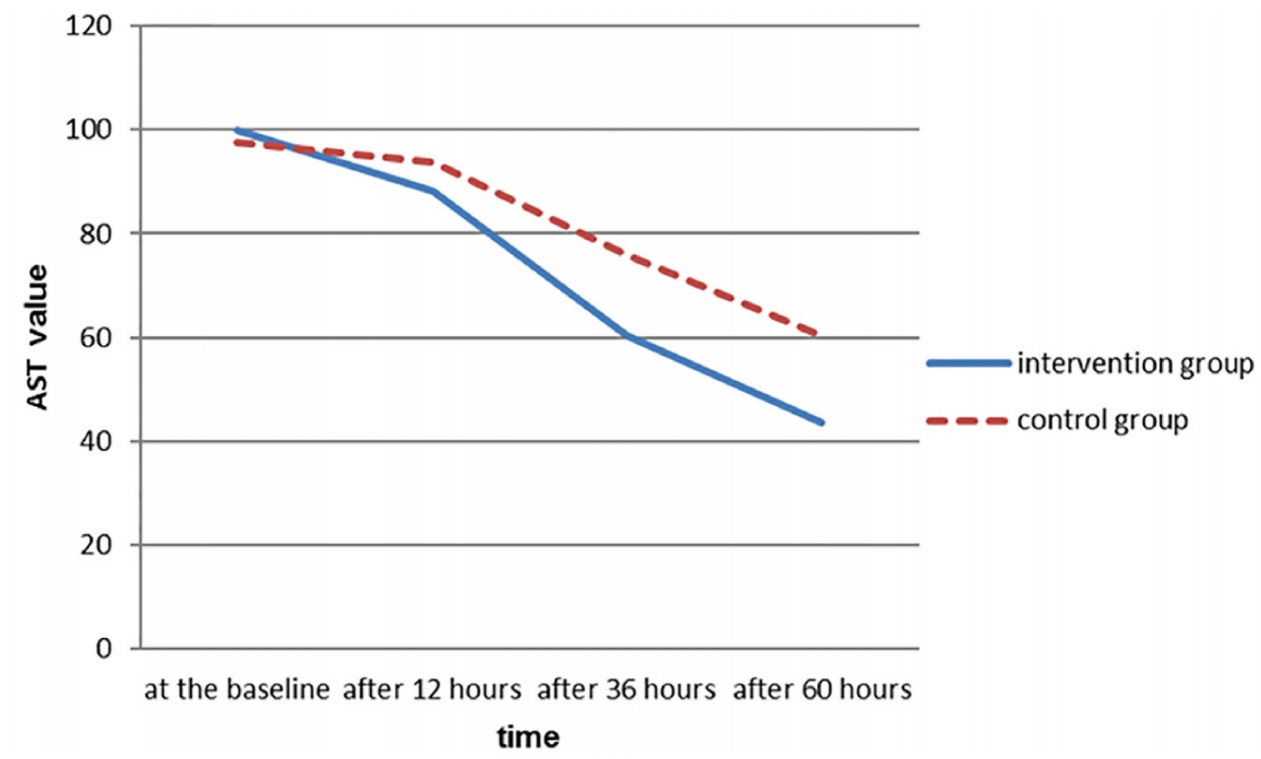

Figure 2. The trend of AST changes in the intervention and control groups during the study

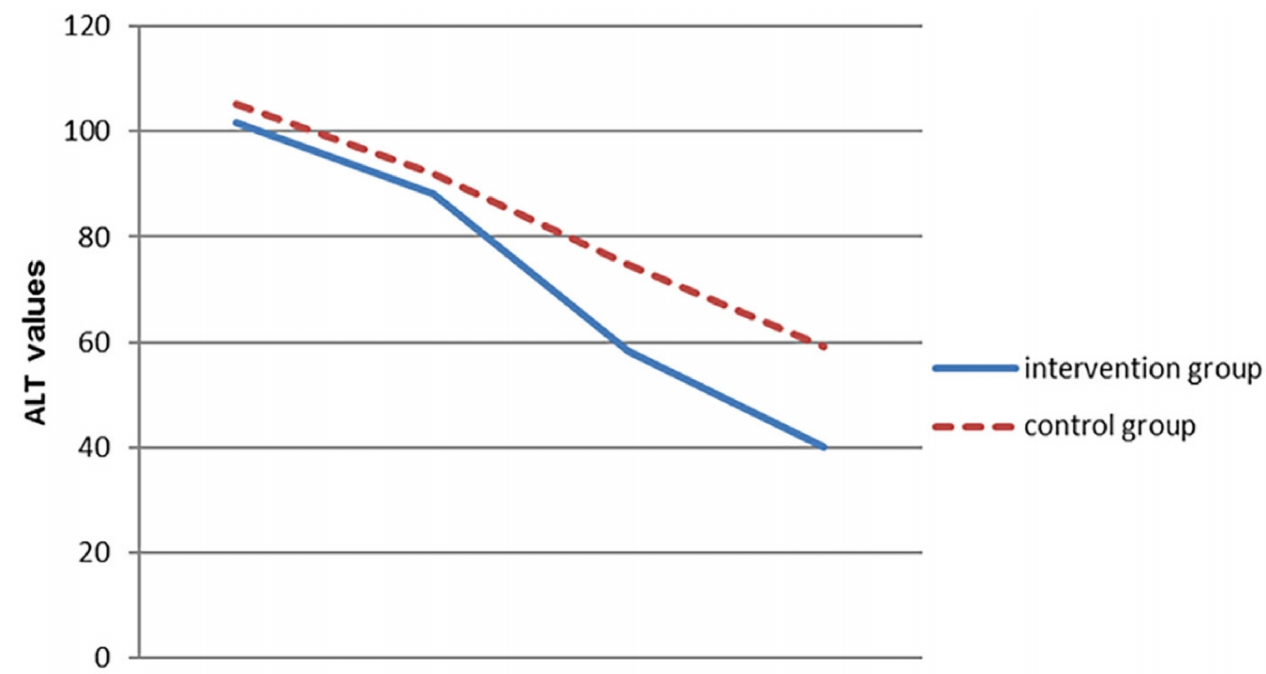

at the baseline after 12 hours after 36 hours after 60 hours

time

Figure 3. Trend of ALT changes in two intervention and control groups during the study

\section{Discussion}

Nowadays, hypertensive disorders are one of the most important and controversial issues in the field of obstetrics. In this study, the effect of antioxidant compositions of silymarin, theoretically impeding the creation and possibly causing restoration of endothelial lesions in improvement of liver and platelet disorders of the mother in severe preeclampsia, was investigated. The plant was officially diagnosed and became available as a drug for clinical use in 1969, and today it is widely used throughout Europe. In examination of the two intervention and control groups in terms of personal characteristics of participants in the study, it was observed that there was no statistical significant differences between two groups in terms of the average age and BMI. Comparing the variables i.e. proteinuria, systolic blood pressure, diastolic blood pressure, LDH, ALP, uric acid, total bilirubin, direct bilirubin, BUN, creatinine, AST and ALT at baseline, there was no significant difference between the two groups. This means that the two groups at the baseline regarding the under studied variables had relatively equal conditions and the impact of confounding factors in the analysis of data obtained during the study was decreased. In multiple studies, good impact of silymarin on improving liver function and liver enzymes in cases such as non-alcoholic fatty liver and 
other liver oxidative damage has been observed and their results are consistent with our study (9-11). In a study in Ireland, the impact of silymarin on inflammatory cytokines produced by mononuclear cells in preeclampsia was investigated. In this study, it was observed that silymarin reduces the secretion of tumor necrosis factor alpha and interleukin 1 beta by PBMC in patients with preeclampsia. It seems that silymarin exerts its antioxidant effects in preeclampsia through these inflammatory mediators (12). In comparing the results of this study evaluating the performance of silymarin at the cellular level with those of our study, it was observed that in both studies, silymarin had shown its antioxidant effects in preeclampsia. But in this study, the impact of silymarin was investigated at cellular level with biochemical approach while our study had a clinical approach to preeclampsia. In one study, the impact of silymarin had been studied in pregnancy while taking contraception pills on thrombophilia and abnormalities in liver enzymes. In this study, silymarin was administered at a dose of $50 \mathrm{mg}$ daily for three months in patients and it was observed that silymarin had no impact on reducing the amount of thrombophilia but it had prevented the development of hepatic disorders (13). The results of this study on the liver protective effect of silymarin is consistent with ours (silymarin in our study also speeded up the improvement of liver enzymes); but in the above-mentioned study, the dose of silymarin was $50 \mathrm{mg}$ daily for three months, while in our study, patients received only two doses of $70 \mathrm{mg}$ of silymarin within 24 hours. It seems that more studies are needed in order to diagnose an effective and safe dose of silymarin. In another study, the protective effect of silymarin in preeclampsia in pregnant Wistar rats was investigated. In this study, $100 \mathrm{mg}$ per $\mathrm{kg}$ of silymarin was daily administered to rats with preeclampsia and at the end of a week's treatment, the amount of hypertension, proteinuria, platelet count, liver histopathology and pregnancy outcome were evaluated. In the group treated with silymarin, a decrease in blood pressure and proteinuria and tumor necrosis factor-alpha and interferon-gamma and interleukin 1Bta in liver and higher platelet counts and improvement of pregnancy outcome was quite obvious and significant. In the group not treated with silymarin, histopathological lesions of the liver in the periportal area included mononuclear infiltration and inflammation and thickening of the tunica muscles in the arteries showed that these changes were less than those of the group receiving silymarin. In this study, no adverse effects resulting from silymarin consumption has been seen in the mother and fetus (14). In comparing this study carried out on pregnant Wistar rats with preeclampsia with our study, it can be seen that in this study, silymarin is effective in reducing blood pressure and increasing in platelet count and reducing proteinuria while such effects had not been observed in our study. This difference may be due to higher doses of silymarin (100 mg per kg per day) in the study. In the above mentioned study, the positive impact of silymarin on liver histopathology was observed and this effect can be coordinated with the results of our study. This difference could be due to higher doses of silymarin (100 mg per kg per day) in the study. In one study, the protective effect of silymarin against the effects of intrauterine exposure to alcohol was examined in SpragueDawley rats. In this study, the group receiving silymarin were reported to have less anatomic problems and more social intelligence (15). Moreover, in another study, the impact of silymarin in reducing alcohol syndrome symptoms in children with alcoholic parents was investigated. The use of silymarin resulted in higher weight and IQ in infants. No harmful effect of silymarin consumption during pregnancy has been reported (16). It appeared that if the safety of silymarin was confirmed during pregnancy, further studies are needed to confirm the effect or lack of effect of the drug in the above-mentioned cases. On the other hand, some studies can also be arranged to examine the impact of silymarin in cases of suffering from preeclampsia before the termination of pregnancy in lengthening the gestational period. In one study, the impact of silymarin in the decrease in jaundice rate was investigated and in this study, silymarin caused a decrease in speed of bilirubin in jaundice. Additionally, in cases in which liver function tests have been abnormal, the use of silymarin accelerated the speed of improvement (17). The impact of silymarin improves liver enzymes in infants in this study, which is consistent with our results. It seems that if the use of Silymarin is proven to be safe, the use of this drug in infants can be facilitated during the postpartum period, and remove the concerns arising from the impact of the drug in breast milk. In a study in Spain, the effect of silymarin along with vitamin $\mathrm{E}$ was evaluated in the treatment of non-alcoholic fatty liver. In this study, the patients were diagnosed and confirmed with incidence of nonalcoholic fatty liver with liver biopsy, the study group were prescribed two silymarin tablets per day (each tablet contains $540 \mathrm{mg}$ of silymarin) plus $36 \mathrm{mg}$ of vitamin E daily for three months and the control group received placebo. Subsequently, it was observed that in the study group, there was a significant reduction in levels of liver enzymes (11). The results of this study are consistent with our study, although the dose of silymarin in this study was much higher than that of our study. In a study in Shiraz, the effect of adding silymarin to the renin-angiotensin inhibitors in reducing proteinuria in type II diabetes was discussed. The study was conducted in patients with type II diabetes mellitus and diabetic nephropathy, in the study group, patients received renin-angiotensin inhibitors alongside two $140 \mathrm{mg}$ silymarin tablets per day for three months when finally proteinuria in the study group had a significant reduction. Furthermore, lipid peroxidation in the study group had also been significantly lower (18). In comparing the results of this research with our results, it was observed that in our study, silymarin had no effect on reducing proteinuria, while in the above-mentioned study, silymarin reduced 
proteinuria in patients with diabetic nephropathy. The reason for this difference may be due to differences in the dose of silymarin in these two studies. However, in this study, silymarin reduced lipid peroxidation and this had not happened in our study. This could be due to the difference in the nature of two illnesses or difference in the dose and duration of consumption.

\section{Limitations of study}

In this study, maternal age and gestational age were confounding factors and by matching the intervention and control groups in the study, the confounding effects were decreased. The parity of patient was another confounding factor in the risk of preeclampsia, and to remove the confounding effect of this factor, only nulliparous women were included in the study. Given the presence of people with BMIs of 20 to 24 in this study, the errors caused by differences in body mass index were minimized.

\section{Conclusions}

In this study, the impact of silymarin on improvement of hepatic abnormalities in patients with severe preeclampsia was discussed. It was observed that there were $\mathrm{s}$ no statistical significant differences between the two groups in terms of the average age and BMI. Comparing the variables i.e. proteinuria, systolic blood pressure, diastolic blood pressure, LDH, ALP, uric acid, total bilirubin, direct bilirubin, BUN, creatinine, AST and ALT at baseline, there was no significant difference between the two groups. This means that the two groups at the baseline regarding the under studied variables had relatively equal conditions and the impact of confounding factors in the analysis of data obtained during the study was decreased. It seems that this drug can be used for accelerating improvement of liver disorders in severe preeclampsia. However, adjusting the dose of drug for the treatment of liver disorders in severe preeclampsia requires further studies. According to findings obtained in this study, it was observed that adding silymarin after termination of pregnancy in patients with severe preeclampsia accelerate the improvement of liver enzymes AST and ALT 36 hours after termination of pregnancy. This results were similar to the results of other studies carried out on silymarin in the treatment of liver disorders. The fact that the levels of liver enzyme after 12 hours of entering the study had not been significantly different between the two groups, may be due to the need for a higher dose or extended time for the effect of treatment with silymarin. In the case of other variables such as the amount of serum lactate dehydrogenase enzyme measured during the study, not affected during the study intervention (treatment with silymarin), It seems that more studies are needed to confirm the effect or lack of effect of antioxidant agents on these cases.

\section{Acknowledgments:}

This is part of an MD thesis dissertation supported with project code 2006 by the Deputy of Research and Technology at Shahrekord University of Medical Sciences. We appreciate the patients and members of the hospital staff for their cooperation.

\section{Clinical trial registration:}

The trial was registered at the Iranian Registry of Clinical Trials (http://www.irct.ir) with the Irct ID: IRCT201509042388/N1.

\section{Funding:}

Shahrekord University of Medical Sciences supported this research (project no. 2006).

\section{Conflict of Interest:}

There is no conflict of interest to be declared.

Authors' contributions:

Both authors contributed to this project and article equally. Both authors read and approved the final manuscript.

\section{References:}

1) Cunninghum FG, Leveno KG, Bloom SL, Hauth JC, Rouse DJ, Spong CY. Williams Obstetrics. 23nd ed. Newyork: McGraw-Hill. 2014; 21: 761-80.

2) von Dadelszen P, Firoz T, Donnay F, Gordon R, Hofmeyr GJ, Lalani S, et al. Preeclampsia in low and middle income countries-health services lessons learned from the PRE-EMPT (PRE-Eclampsia-Eclampsia Monitoring, Prevention and Treatment) project. J Obstet Gynaecol Can. 2012; 34(10): 917-26. PMID: 23067947. 
3) Engelhardt T, MacLennan FM. Fluid management in pre-eclampsia. Int J Obstet Anesth. 1999; 8(4): $253-9$. doi: 10.1016/S0959-289X(99)80106-X. PMID: 15321120.

4) Hutcheon JA, Lisonkova S, Joseph KS. Epidemiology of preeclampsia and the other hypertensive disorders of pregnancy. Best Pract Res Clin Obstet Gynaecol. 2011; 25(4): 391-403. doi: 10.1016/j.bpobgyn.2011.01.006. PMID: 21333604.

5) Masoudi M, Miraj S, Rafieian-Kopaei M. Comparison of the Effects of Myrtus Communis L, Berberis Vulgaris and Metronidazole Vaginal Gel alone for the Treatment of Bacterial Vaginosis. J Clin Diagn Res. 2016; 10(3): 4-7. doi: 10.7860/JCDR/2016/17211.7392. PMID: 27134945, PMCID: PMC4843330.

6) Miraj S, Rafiean Kopaei M, Kiani S. Melissa officinalis L: A Review Study with an Antioxidant Prospective. Journal of Evidence-Based Complementary \& Alternative Medicine. 2016; 21(4). doi: $10.1177 / 2156587216663433$.

7) Seyyedi F, Rafiean-Kopaei M, Miraj S. Comparison of the Effects of Vaginal Royal Jelly and Vaginal Estrogen on Quality of Life, Sexual and Urinary Function in Postmenopausal Women. J Clin Diagn Res. 2016; 10(5): 1-5. doi: 10.7860/JCDR/2016/17844.7715. PMID: 27437306, PMCID: PMC4948482.

8) Miraj S, Kaveh Baghbahadorani F. The impact of Silymarin on antioxidant capacity of serum and lipid peroxidation in patients with severe pre-eclampsia. Der Pharmacia Lettre. 2016; 8(6): 29-32.

9) Baghbahadorani FK, Miraj S. The impact of Silymarin on improvement of platelet abnormalities in patients with severe preeclampsia. Electron Physician. 2016; 8(5): 2436-42. doi: 10.19082/2436. PMID: 27382456, PMCID: PMC4930266.

10) Feher J, Lengyel G. Silymarin in the prevention and treatment of liver diseases and primary liver cancer. Curr Pharm Biotech. 2012; 13(1): 210-7. PMID: 21466434.

11) Pellegrini L, Belcaro G, Dugall M, Hu S, Gizzi G, Corsi M, et al. Supplementary management of functional, hepatic damage with Liverubin (pharma-standard Silymarin). A 3-month registry. Minerva Gastroenterol Dietol. 2015. PMID: 26448308.

12) Aller R, Izaola O, Gómez S, Tafur C, González G, Berroa E. Effect of silymarin plus vitamin E in patients with non-alcoholic fatty liver disease. A randomized clinical pilot study. Eur Rev Med Pharmacol Sci. 2015; 19(16): 3118-24. PMID: 26367736.

13) Giorgi VS, Peracoli MT, Peracoli JC, Witkin SS, Bannwart-Castro CF. Silibin modulates the NF-kb pathway and proinflammatory cytokine production by mononuclear cells from preeclamptic women. J Reprod Immunol. 2012; 95(1-2): 67-72. doi: 10.1016/j.jri.2012.06.004. PMID: 22871551.

14) Martines G, Piva M, Copponi V, Cagnetta G. [Silymarin in pregnancy and during hormonal contraceptive treatment. Blood chemistry and ultrastructural findings in the experimental model]. Arch Sci Med (Torino). 1979; 136(3): 443-54. PMID: 549550.

15) Souza CO, Peraçoli MT, Weel IC, Bannwart CF, Romão M, Nakaira-Takahagi E. Hepatoprotective and anti-inflammatory effects of silibin on experimental preeclampsia induced by L-NAME in rats. Life sci. 2012; 91(5-6): 159-65. doi: 10.1016/j.lfs.2012.06.036. PMID: 22781706.

16) Reid C, Edwards J, Wang M, Manybeads Y, Mike L, Martinez N, et al. Prevention by a silymarin phospholipid compound of ethanol induced social learning deficits in rats. Planta Med. 1999; 65(5): $421-4$. doi: 10.1055/s-1999-14085. PMID: 10418328 .

17) La Grange L, Wang M, Watkins R, Ortiz D, Sanchez ME, Konst J, et al. Protective effects of the flavonoid mixture silymarin on fetal brain and liver. J Ethnopharmacol. 1999; 65(1): 53-61. PMID: 10350368.

18) Kassem LM, Abdelrahim MEA, Naguib HF. Investigating the efficacy and safety of silymarin in management of hyperbilirubinemia in neonatal jaundice. Med Sci. 2013; 2(2): 575-90. doi: 10.5455/medscience.2013.02.8057.

19) Fallahzadeh MK, Dormanesh B, Sagheb MM, Roozbeh J, Vessal G, Pakfetrat M, et al. Effect of addition of silymarin to renin-angiotensin system inhibitors on proteinuria in type 2 diabetic patients with overt nephropathy: a randomized, double-blind, placebo-controlled trial. Am J Kidney Dis. 2012; 60(6): 896-903. doi: 10.1053/j.ajkd.2012.06.005. PMID: 22770926. 